\title{
Nature, availability, and utilization of women-focused cardiac rehabilitation: a systematic review
}

Taslima Mamataz ${ }^{1,2}$, Gabriela L. M. Ghisi ${ }^{2}$, Maureen Pakosh ${ }^{3}$ and Sherry L. Grace ${ }^{1,4^{*}}$

\begin{abstract}
Background: Women do not participate in cardiac rehabilitation (CR) to the same degree as men; women-focused CR may address this. This systematic review investigated the: (1) nature, (2) availability, as well as (3a) utilization of, and (b) satisfaction with women-focused CR.
\end{abstract}

Methods: Medline, Pubmed, Embase, PsycINFO, CINAHL, Web of Science, Scopus and Emcare were searched for articles from inception to May 2020. Primary studies of any design were included. Adult females with any cardiac diseases, participating in women-focused CR (i.e., program or sessions included $\geq 50 \%$ females, or was 1-1 and tailored to women's needs) were considered. Two authors rated citations for inclusion. One extracted data, including study quality rated as per the Mixed-Methods Assessment Tool (MMAT), which was checked independently by a second author. Results were analyzed in accordance with the Synthesis Without Meta-analysis (SWiM) reporting guideline.

Results: 3498 unique citations were identified, with 28 studies (53 papers) included (3697 women; $\geq 10$ countries). Globally, women-focused CR is offered by $40.9 \%$ of countries that have CR, with $32.1 \%$ of programs in those countries offering it. Thirteen (46.4\%) studies offered women-focused sessions (vs. full program), 17 (60.7\%) were women-only, and 11 (39.3\%) had gender-tailoring. Five (17.9\%) programs offered alternate forms of exercise, and 17 (60.7\%) focused on psychosocial aspects. With regard to utilization, women-focused CR cannot be offered as frequently, so could be less accessible. Adherence may be greater with gender-tailored CR, and completion effects are not known. Satisfaction was assessed in 1 trial, and results were equivocal.

Conclusions: Women-focused CR involves tailoring of content, mode and/or sex composition. Availability is limited. Effects on utilization require further study.

Keywords: Cardiac rehabilitation, Women, Systematic review, Healthcare utilization, Adherence, Heart diseases, Secondary prevention, Access, Satisfaction, Health services delivery

\section{Introduction}

Cardiovascular diseases (CVDs) are among the leading causes of morbidity and mortality in women globally [1]. It has been well-recognized that more attention needs to be paid to women's cardiovascular health due

\footnotetext{
*Correspondence: sgrace@yorku.ca

${ }^{1}$ Faculty of Health, York University, Bethune 368, 4700 Keele Street, Toronto, ON M3J 1P3, Canada

Full list of author information is available at the end of the article
}

to their poorer outcomes than men, such as more disability, hospitalization and early mortality [2]. This is likely due to the ways CVD risk factors are manifested differently in women (e.g., tobacco use and oral contraceptives, diabetes more hazardous, low socioeconomic status more preponderant as well as depression $[3,4])$. Moreover, diagnostic tests are less sensitive in women [5], which is related to the fact that they often have different forms of CVD (e.g., heart failure with 
preserved ejection fraction, myocardial infarction with non-obstructive coronary arteries, coronary artery dissection and vasospasm) [6], and results in women being diagnosed at later stages of disease than men [5]. Finally, women have a greater burden of some comorbidities than men [6].

Cardiac rehabilitation (CR) is a standardized model of secondary preventive care proven to mitigate this burden. It offers the core components of risk factor management, structured exercise, patient education and psychosocial counselling [7], in a clinical or home-based setting, offered on average over 4 months [8]. It is established that CR participation results in approximately $20 \%$ lower mortality and morbidity [9], improved quality of life [10], and is cost-effective [11]. Indeed, CR is recommended for women in clinical practice guidelines [12].

Despite these benefits, CR is under-utilized globally [13], especially in women. Meta-analyses show fewer women than men are referred to CR programs (39\% women vs. 49\% men) [14]. Even after being referred, women are less likely than men to enroll (38.5\% vs. $45.0 \%)$ [15] and adhere (64.2\% vs. $68.6 \%)$ [16] to prescribed sessions. Reasons for women's under-utilization are multifactorial, including lack of awareness due to less provider endorsement [17], transportation barriers, family obligations and experiencing exercise as tiring or painful, often related to their greater comorbidities $[18,19]$. Women also have different $C R$ preferences than men, and many of their preferences are not well-met [20-22]. For example, women prefer engaging in yoga or dance as forms of exercise rather than using treadmills or cycle ergometers, and they prefer not being rushed, crowded or weighed (the latter two related to desire for privacy).

To address these gender-specific issues, "womenfocused" (also termed "gender-tailored" [which we consider to mean that content is adapted to women's needs and preferences], or "women-only" [meaning the sex composition of CR programming only comprises women] in the literature, among other terms) sessions or full programs have been developed, to attempt to address their barriers and meet their unique needs [23, 24]. Indeed, it is important that in the field we start to better delineate what kind of women-focused CR is being delivered, in terms of how or whether the following characteristics/elements are present (not mutually-exclusive): (a) women-only or mostly women (also considering individually-delivered care [in-person or remote] which is inherently "women-only", particularly if the healthcare provider(s) is female), (b) content tailored to women (and specifically what and how), and/or (c) some versus the full program is either (a) and/or (b) (e.g., peer support sessions for women, a separate education session for women; Table 1).
Extrapolating from the International Council of Cardiovascular Prevention and Rehabilitation's (ICCPR) global $\mathrm{CR}$ audit, it is estimated there are 686 programs in 45 countries globally offering some form of women-focused programming [25]; this is $41 \%$ of countries that have any $\mathrm{CR}$. However, the nature of what is being offered in the "real-world" is not known. Indeed, there has only been one review in this area, which is published only as an abstract. While this work is an advance, they focused only on randomized trials which may not represent what is available in the real-world. They identified 10 trials, with very little detail provided regarding how they are women-focused.

This also leaves questions regarding whether the nature of women-focused $\mathrm{CR}$ as delivered can improve utilization [13] (i.e., are women more likely to enrol if these types of models are available? Are they more likely to adhere and complete the programs?), and whether it does better meet women's needs (e.g., satisfaction). Therefore, the objectives of this systematic review were to investigate the: (1) nature and (2) availability of women-focused CR (e.g., how delivered, tailoring), as well as (3) effects on (a) utilization and (b) satisfaction.

\section{Methods}

The protocol for this systematic review was registered prospectively on PROSPERO (CRD42020189760). Methods were based on the Cochrane Handbook for Systematic Reviews of Interventions [26]. The review was conducted in accordance with the Preferred Reporting Items for Systematic Reviews and Meta-Analyses (PRISMA) 2020 guidelines [27].

\section{Inclusion/exclusion criteria}

Primary studies of any design, such as randomized trials as well as observational and qualitative studies, were included. In terms of publication type, conference abstracts were included where identified, but the authors were contacted where possible to determine if a full publication was available, and if not, to get further needed details. Theses/dissertations were included. Reviews and editorials were searched to identify primary studies only. Case studies were also excluded.

The CR program had to offer at least initial assessment, structured exercise (supervised or unsupervised), and at least one other strategy to control risk factors [7]. To be considered "women-focused", CR sessions (e.g., education or exercise components of an overall $\mathrm{CR}$ program or peer support) or programs had to include $\geq 50 \%$ females. Individually-delivered programs (e.g., home-based or eCR; are generally inherently $100 \%$ women) were included if they were tailored to women's needs or preferences in some way (note this criteria was not specified a 


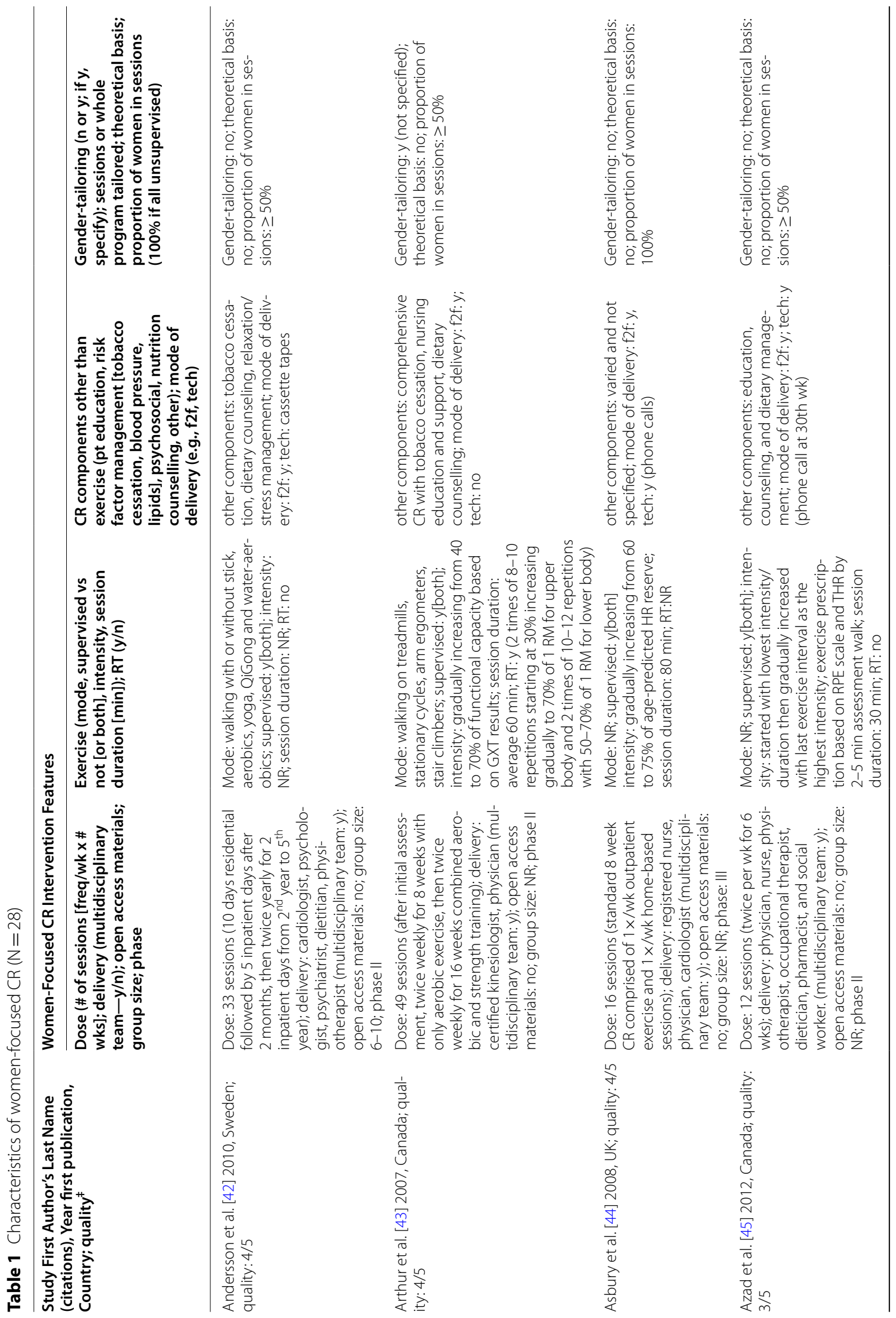




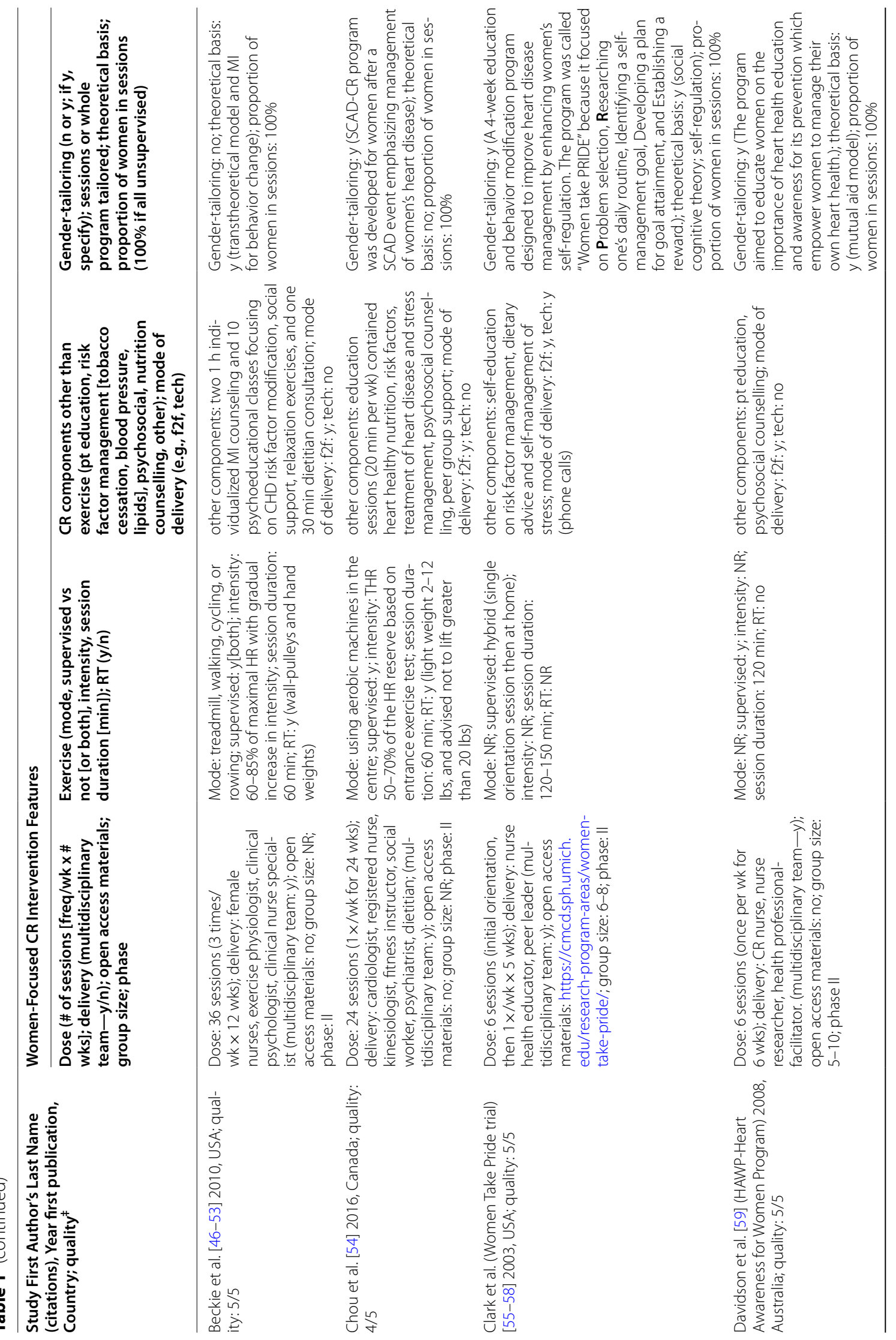




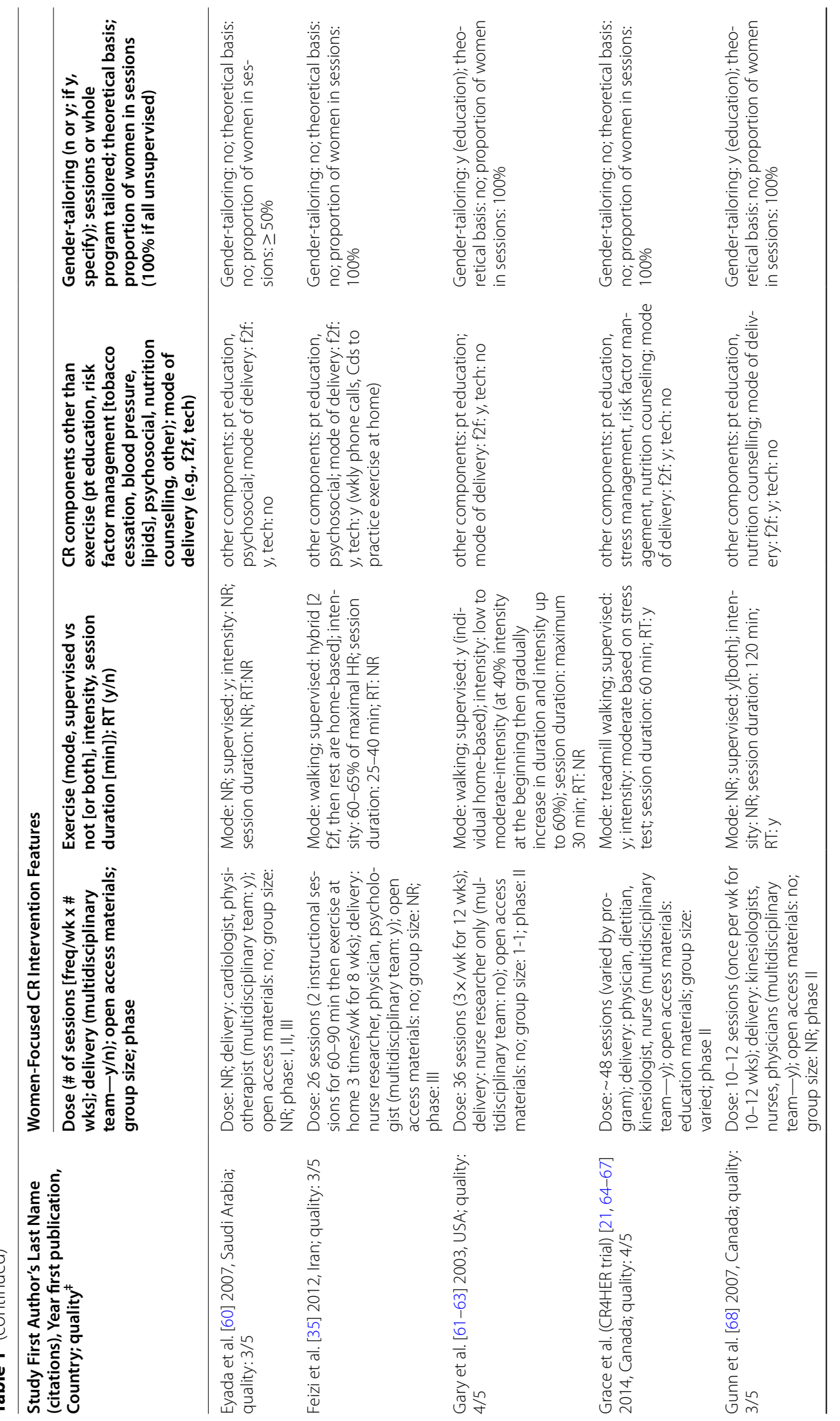




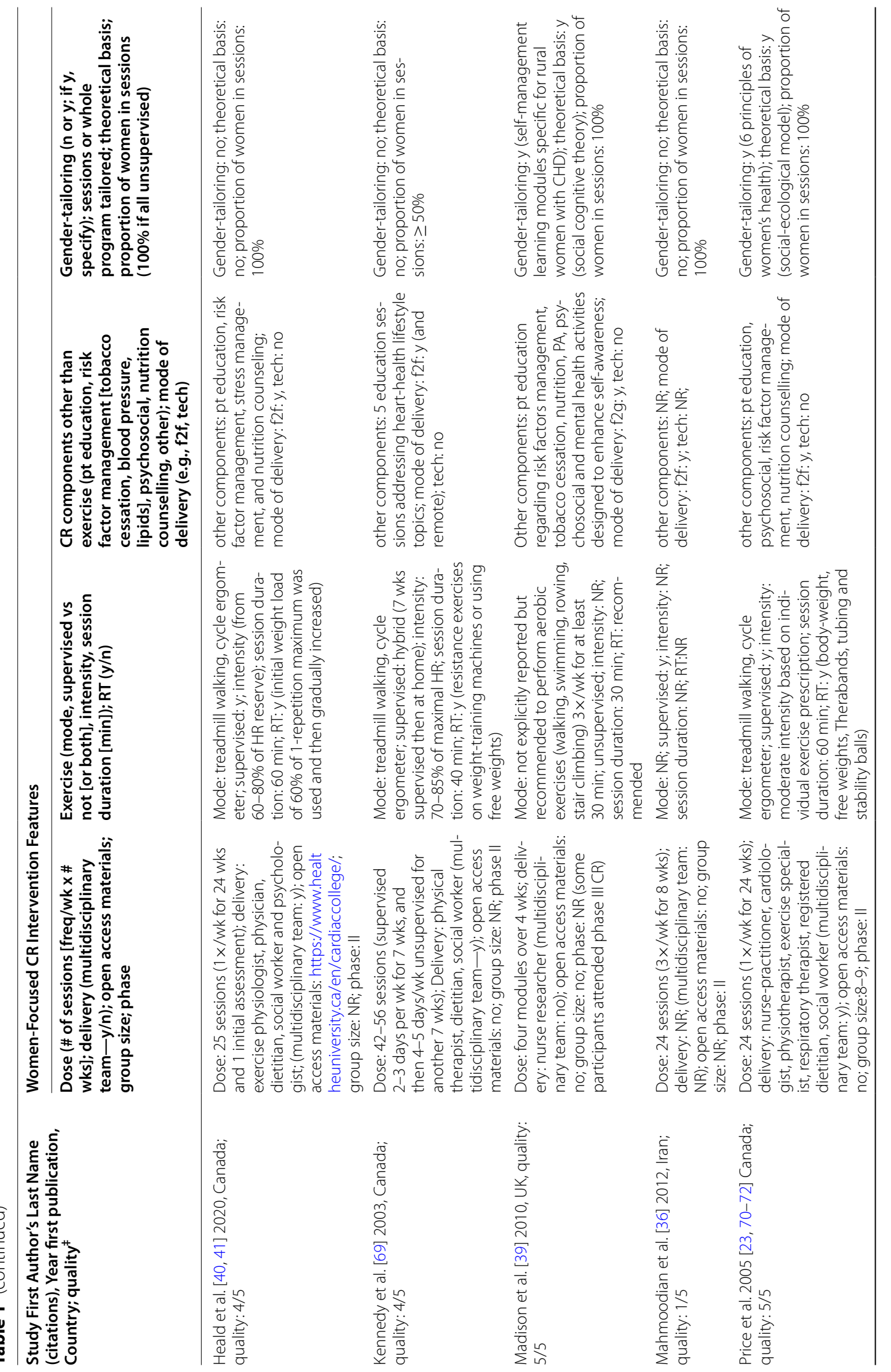




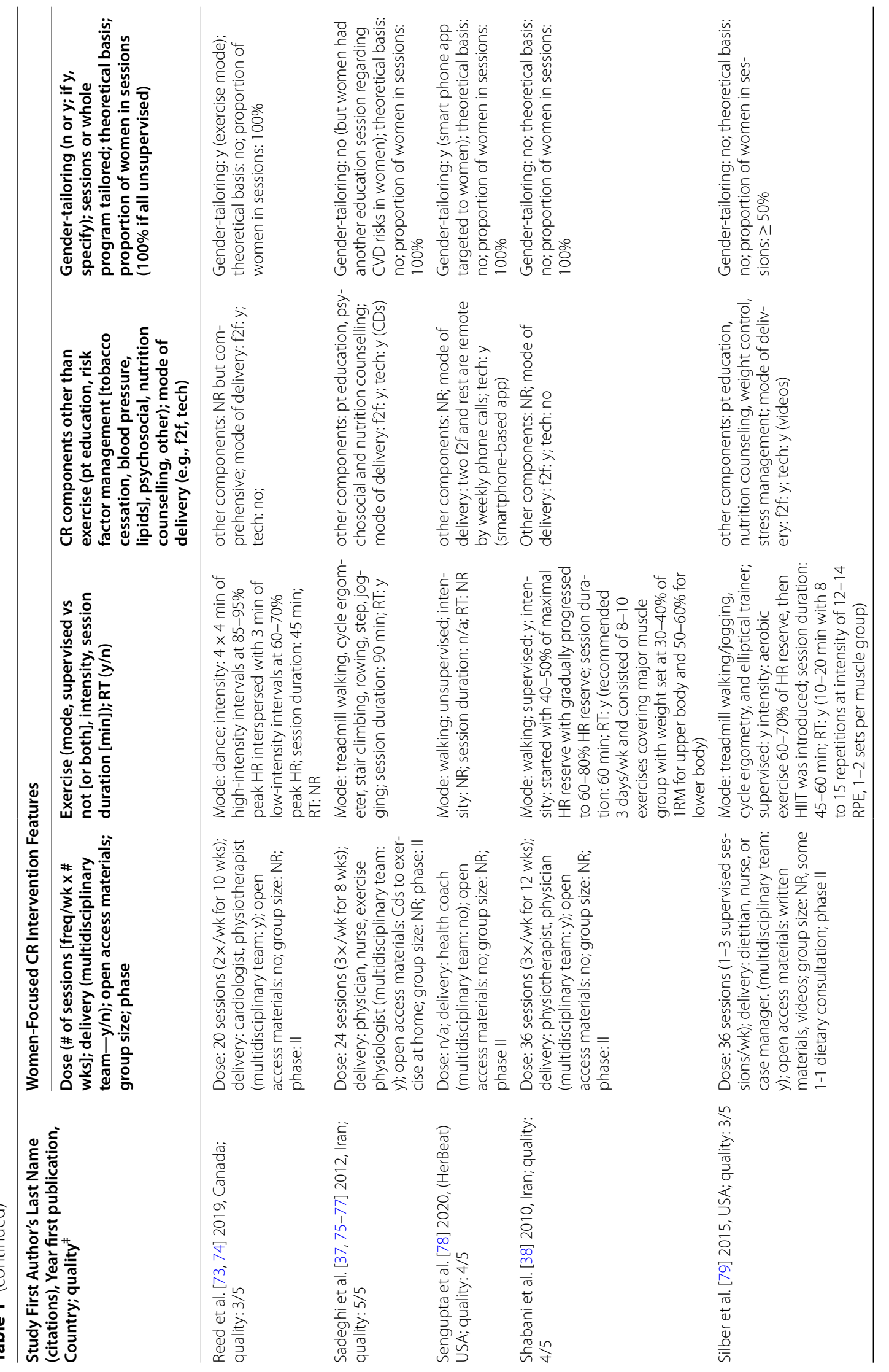




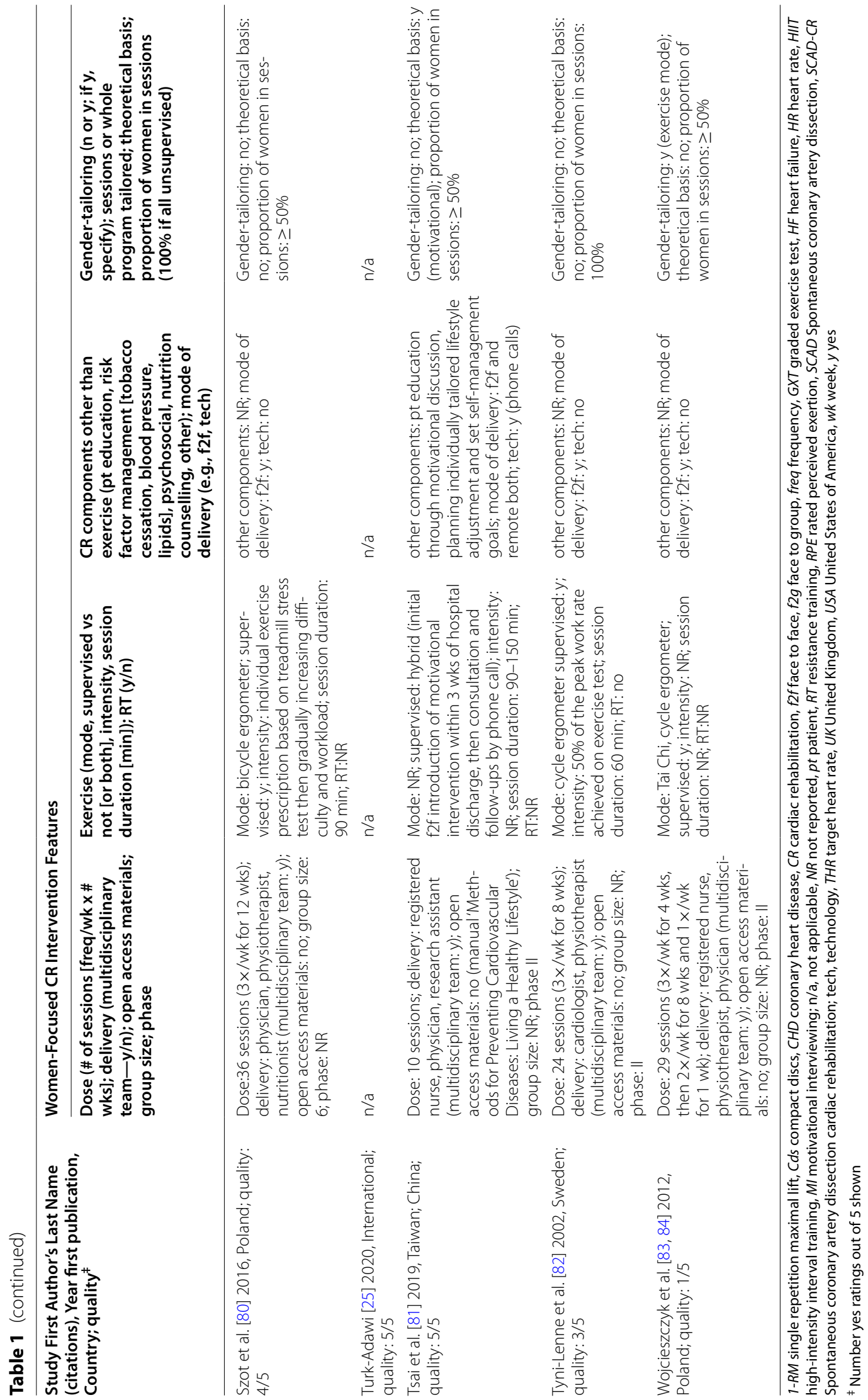


priori, but at the time of resolving citation rating discrepancies). We distinguished by phase of CR (i.e., I or inpatient, II or outpatient, and III/IV or maintenance).

Studies that included female adults (ages 18 years or over) with any cardiac conditions were included. The study could have any outcome, given that it was the first review in this area. This paper reports on the outcomes of access, utilization, satisfaction. Clinical, psychosocial and cost outcomes are reported elsewhere [28].

\section{Search strategy}

Eight electronic databases were searched from their inception to May 2020, namely: APA PsycInfo (Ovid), Medline (Ovid), Pubmed (non-Medline), Embase (Ovid), Web of Science Core Collection, Scopus, CINAHL (Cumulative Index to Nursing \& Allied Health Literature) (EbscoHost) and Emcare (Ovid). The search strategies were developed in collaboration with an Information Specialist utilizing the PICO framework, subject headings as appropriate for each database, and free-text terms relevant to the topical concepts. No language limits were applied. A sample search strategy for Medline is shown in online (see Additional file 1).

\section{Study selection}

Duplicate citations from the search of the databases were deleted in Mendeley, with the unique citations then imported into Covidence. After training and calibration, two researchers (TM and GMG) independently considered the abstracts of potentially-eligible articles for inclusion. The full-texts of potentially-eligible citations were then considered to ascertain whether they met eligibility criteria. Where unclear, authors were contacted to ascertain whether the CR programs had more than $50 \%$ women. For both stages, any disagreements were resolved by the senior researcher (SLG). Once the studies were identified, any related protocol manuscripts, theses/dissertations or publications on the baseline cohort for example were secured to inform data extraction and quality assessment.

\section{Data extraction and management}

Information regarding the study design, sample, nature of the CR program, and outcomes reported were extracted from the included studies. For study design, whether there were any comparison groups was extracted, and if yes, whether they were usual care (UC; i.e., with no CR) or active comparisons (AC; e.g., traditional or homebased CR, components of secondary prevention) groups. In addition, the quality of included studies was assessed using the Mixed-Methods Assessment Tool [29], which is applicable to multiple designs. For each of 5 designs, there are 5 items, which are rated as being present (yes), not present, or indeterminable.

Following training by SLG and GMG, TM independently extracted data for each included study, and rated their quality. A second author (GMG) then independently reviewed the extraction and ratings. Any disagreements were resolved by discussion or, where agreement could not be reached, by consultation with the senior author (SLG; except in relation to quality assessment of studies in which she was involved, to mitigate potential bias).

\section{Data synthesis}

All study results were synthesized tabularly, ordered alphabetically by first author, with key study characteristics summarized. First, the summary of the nature of women-focused CR was qualitative (e.g., gender-tailoring) and quantitative (e.g., sum of studies where CR was all women, whether the women's aspect comprised the full program or only sessions; as well as whether CR was supervised, group-based, as well as frequency of exercise modes, components, team members). Next, availability information was summarized qualitatively.

For the third objective examining utilization and satisfaction, in accordance with the Synthesis Without Metaanalysis reporting guideline [30], results were grouped by outcome, and then by comparison type (UC or AC, if applicable), with studies of higher-quality design summarized first (i.e., prioritized randomized trials, followed by controlled studies, and then others). Outcome scores at each available assessment point were summarized, as well as tests of effects by group and/or time; Vote counting of significant effects ( $p$-values) by direction was undertaken.

\section{Results}

\section{Study search and selection}

Overall, 3498 unique citations were identified. Upon screening titles and abstracts, four reviews identified were hand-searched [31-34]. No title or abstract was identified in a non-English language which would be considered for full-text review. Four studies from Iran were identified [35-38], and authors were contacted in some instances to confirm female composition and ascertain any tailoring; ultimately these studies were included as they offer only women-only CR there. There was discussion about whether the study by Madison et al. [39], met inclusion criteria of offering structured exercise, but ultimately this study was included. One study undertaken by our group that meets inclusion criteria was recently completed, and was added [40, 41]. Ultimately, 28 studies (53 publications) that met the eligibility criteria were included (Fig. 1) [21, 23, 25, 35-84]. 


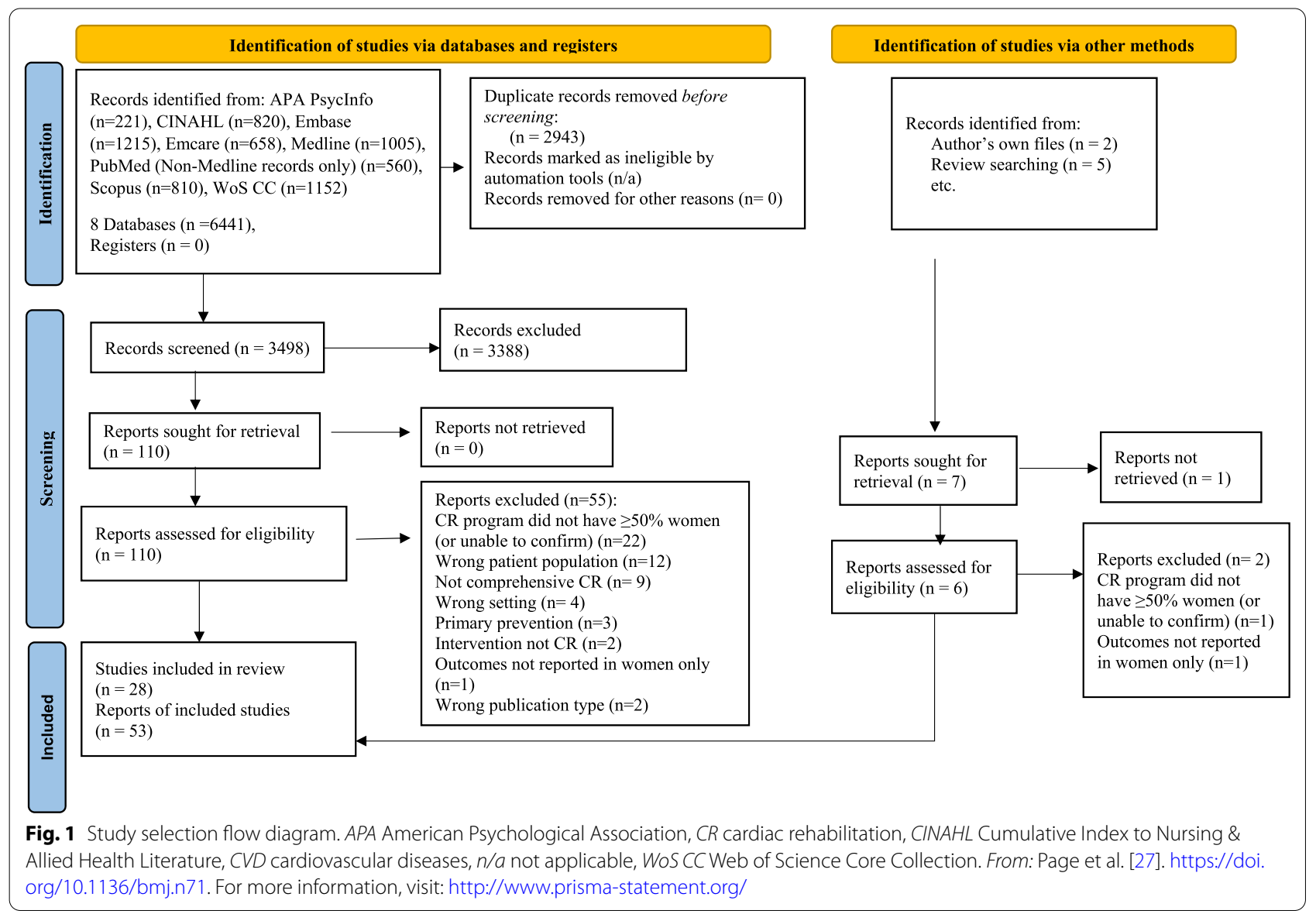

\section{Study characteristics}

As shown in Table 1, the first study was published in 2002. Studies were from the following $>10$ countries: 9 (32.1\%) from Canada, 5 (17.9\%) from the United States of America, 4 (14.3\%) from Iran, 2 (7.1\%) from United Kingdom, 2 (7.1\%) from Poland, 2 (7.1\%) from Sweden, 1 (3.6\%) was international [25], and 1 (3.6\%) each stemmed from Australia, Taiwan/China), as well as Saudi Arabia. The Southeast Asian and African regions are not represented (likely reflective of the fact that both have very little CR) [85]. Only Iran is a non-high-income country [86]. Six (21.4\%) studies were multi-centre; not considering the global audit of women-focused CR [25], ultimately 44 centers were studied.

With regard to design, 11 (39.3\%) of the included studies were randomized trials, some with more than 2 arms. Five (45.4\%) had UC control arms; Of those 9 with AC, these included: traditional supervised CR, hybrid models (i.e., supervised sessions transitioning to remote), homebased CR, structured exercise only, education only, Tai Chi, relaxation therapy, and cognitive-behavioral psychotherapy [83, 84]. The remaining 17 studies were prospective cohort $(n=14,82.4 \%$; of which $n=8$ had control groups), mixed-methods ( $\mathrm{n}=2,11.8 \%)$ or descriptive $(\mathrm{n}=1,5.8 \%)$ in design. Duration of follow-up ranged from 1 to 60 months (5 years [42]), with a median of 3 months.

Quality of each study is also shown in Table 1. The median number of yes' (indicating good quality) per study was $4 / 5$.

\section{Participants}

Sample sizes across studies ranged from 9 to 727 participants, with a median of 60 . In all but 2 (92.9\%) studies, the samples were comprised of only female participants; in the other two studies, women were compared with a sample of male participants [40, 41, 76]. Overall, there were 3697 women studied.

Mean age of included women participants was $59.3 \pm 7.1$ years (standard deviation). Ethnocultural background was reported in 7 (25.0\%) studies, which mostly comprised white caucasians. Most participants (41.1\%) had coronary artery disease, however other diagnosis more common in women were also represented such as: spontaneous coronary artery dissection (SCAD; 2 studies with 79 women $[54,79]$ ), ischemia with no obstructive 
coronary artery disease (INOCA; 3 studies with 143 women [44, 80, 82]), and heart failure only (2 studies with 83 women $[45,61])$.

\section{Nature of women-focused CR}

Twenty-three (82.1\%) studies tested phase II (outpatient) CR, $3(10.7 \%)$ were phase III $[35,39,44]$, and one study covered phases I, II and III [60]. In 22 (78.6\%) studies, CR was delivered in a clinical setting such as a hospital only, and in $5(16.1 \%)$ it was primarily remote (e.g., homebased, technology) (Table 1; 1 study assessed availability so not listed here) [25]. In 9 (32.1\%) studies, some form of technology was used (e.g., telephone, remote monitoring, smartphone apps). CR was offered individually rather than in groups in 2 (7.1\%) studies (i.e., home-based, inperson [61]; in-person for initial orientation then complete the program at home [55]).

There was a range of 4-56 sessions/program overall $($ median $=24)$. Thirteen $(46.4 \%)$ studies offered only women-focused sessions (with an average of 14.2 such sessions/program, where reported) [23, 39-41, 43, 46, 54, $55,59,61,64,68,73,78]$, with the remainder of studies testing full women-focused programs (Table 1).

All CR programs incorporated aerobic exercise of some mode (i.e., treadmill, cycle ergometer, walking or stair climbing); 10 (35.7\%) had resistance exercise. In 5 (17.9\%) studies, there were alternative forms of exercise (e.g., Tai Chi, dance, aerobics, yoga, Qigong, water aerobics; Table 1). Seventeen (60.7\%) studies had a psychosocial component (e.g., meditation, progressive muscle relaxation, cognitive-behavioural techniques). Types of healthcare providers delivering services are shown in Table 1 , with $23(82.1 \%)$ studies having more than 1 profession (i.e., multidisciplinary team).

With regard to how interventions were designed to meet women's needs (Table 1), in 17 (60.7\%) studies the CR included no men (in the 4 studies from Iran, as outlined above, women only participate in women-only programs for cultural reasons [35-38]) and 11 (39.3\%) had some form of gender-tailoring of content other than form of exercise as outlined above (with many studies having both, and others mostly women with or without tailoring). With regard to the latter content, in 9 (32.1\%) studies, education was tailored to consider women-specific information needs, such as regarding risk factors, forms of CVD and comorbidities more common in women.

\section{Availability, utilization and satisfaction with women-focused $C R$}

Availability of women-focused CR sessions or programs around the world was summarized in the introduction [25]. In that 2016 audit, women-focused CR was estimated to be available in 45 countries. Through this review we identified Sweden, Taiwan and Saudi Arabia also offer it. The audit revealed women-focused CR programs were most commonly-available in the Eastern Mediterranean region and Europe, with North America relatively more represented in this sample. On average, $1 / 3$ of programs in a country with women-focused CR offered it.

With regard to $C R$ accessibility, a qualitative study reported that the process of learning about the womenonly program and obtaining physician referral were among the barriers in accessing women-only CR [70]. Two studies from Toronto identified that women-focused CR may be less accessible because it inherently cannot be offered as frequently as mixed-sex CR. For instance, in the CR4HER trial, many women did not follow random allocation and switched from women-only to mixed-sex program models; semi-structured interviews revealed this was due to time conflicts with the only one available time per week the women-only program sessions were offered [21]. In the other study at the same centre, participants could elect women-only, mixed sex or home-based models. Only $22.0 \%$ elected women-only, and they were less often working, so likely had more time flexibility [40].

With regard to $C R$ utilization, first, enrolment (i.e., attendance at initial visit) was considered. In Beckie et al's trial, $89.2 \%$ initiated the traditional mixed-sex CR and $97.2 \%$ initiated the women-focused program [47]. In Azad et al's trial, of 51 heart failure participants randomized to the women-focused CR group, 8 dropped out (84.3\% enrolment; no comparative data available). This was not reported by group in most studies, and in no studies was it inferentially tested by group, so receipt of allocated intervention was extracted from all trials as a proxy for descriptive purposes at the least (Table 2). For example, in the CR4HER trial, $63.6 \%$ of women allocated to women-only CR, $67.8 \%$ allocated to mixed-sex and $43.6 \%$ allocated to home-based CR attended the initial visit at CR in their allocated model [64]. Overall, "enrolment' in women-focused CR arms was on average $93.7 \%$, and in $\mathrm{AC}$ arms was $87.2 \%$.

With regard to program adherence (or percentage of prescribed sessions attended), 5 studies reported on this, including 2 trials which will be summarized first. In Beckie et al.s trial in the United States, adherence to the 36 women-only sessions with motivational interviewing was significantly greater than traditional CR [51]. In the CR4HER trial, adherence to all models was modest $(54.5 \%)$, and did not differ by model on a per-protocol basis; as-treated, it appeared that women were more likely to adhere to home-based than either women-only or traditional supervised $\mathrm{CR}$, however this should be interpreted with caution as women can more easily participate in CR phone calls than travel for site visits, and 


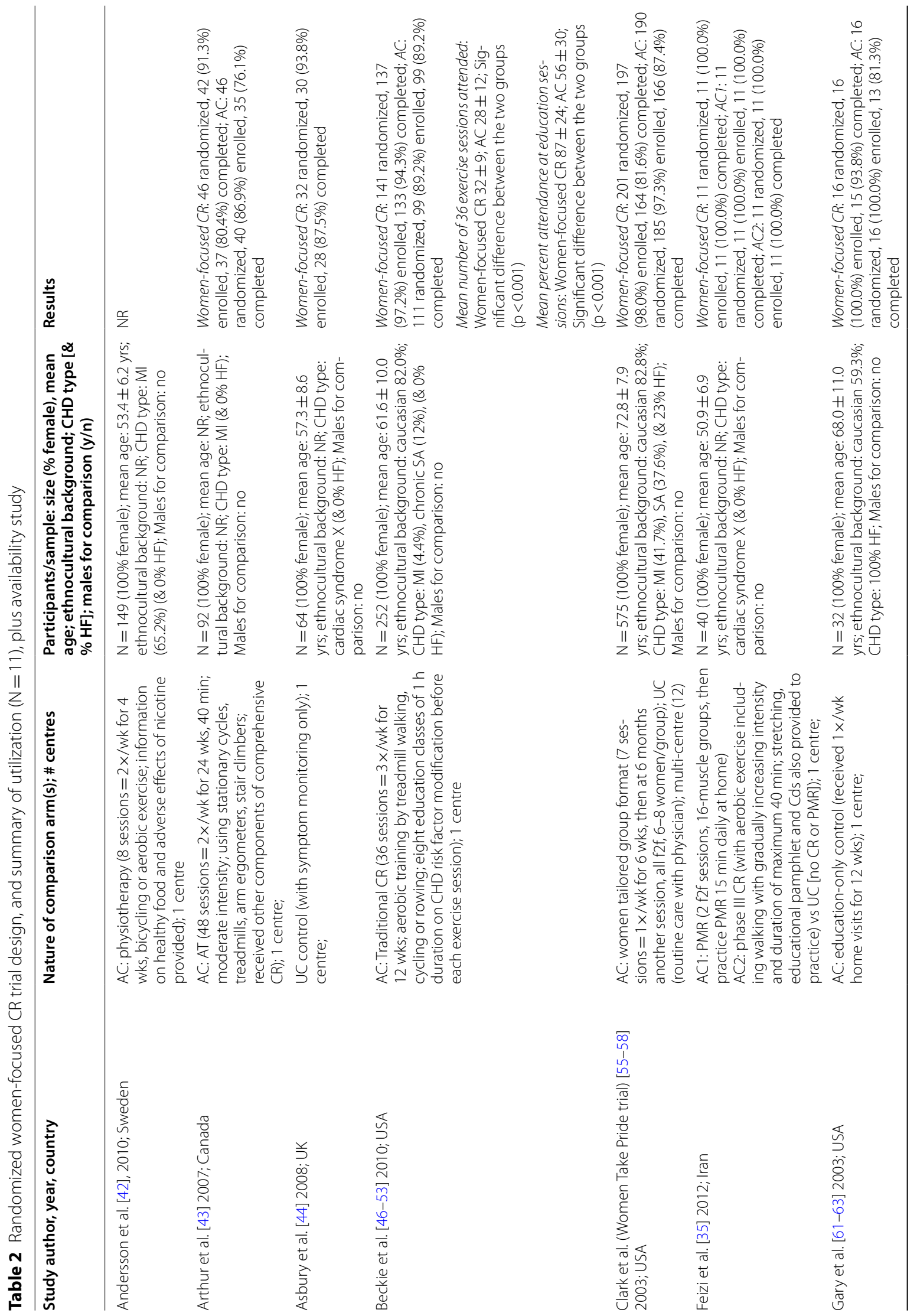




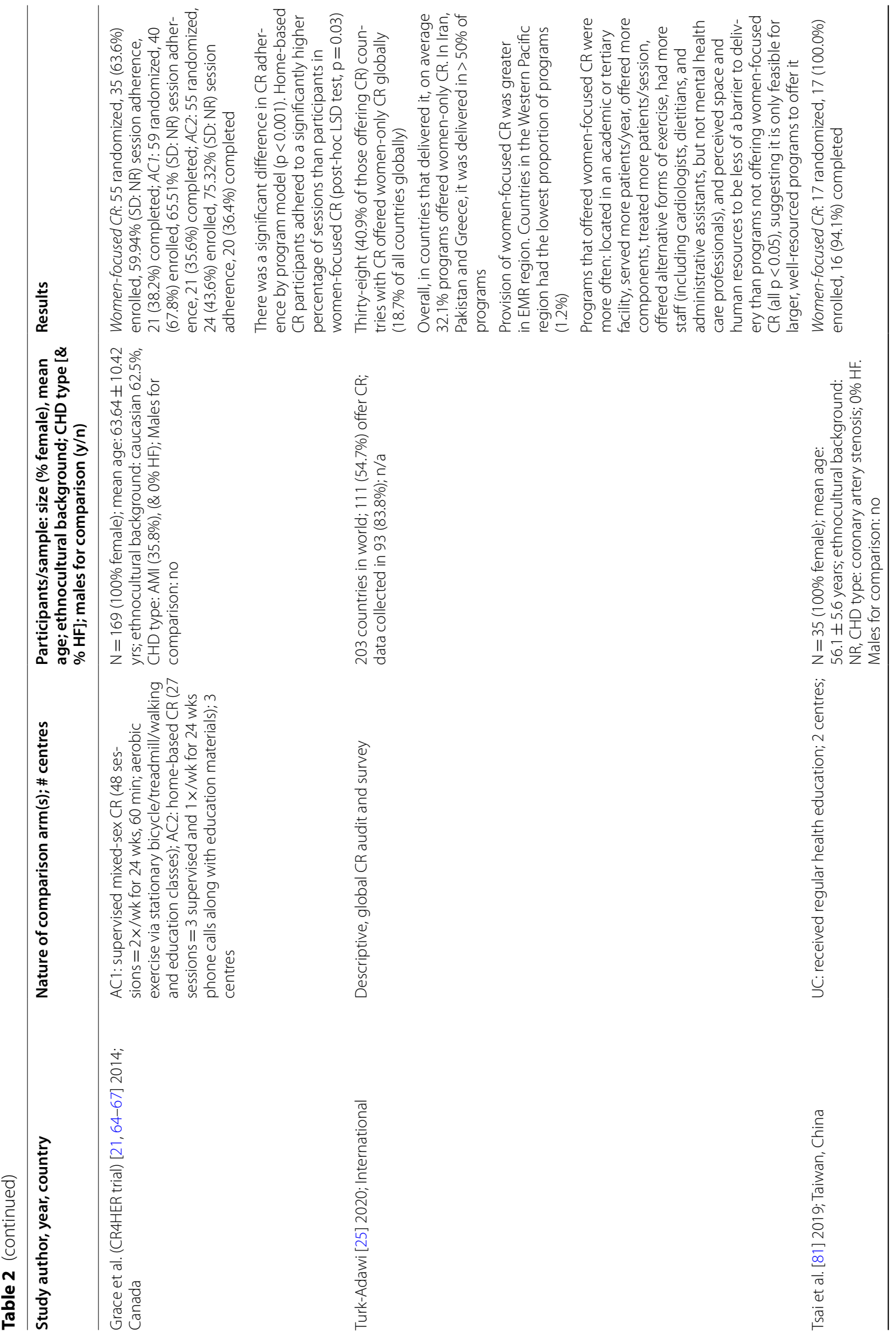




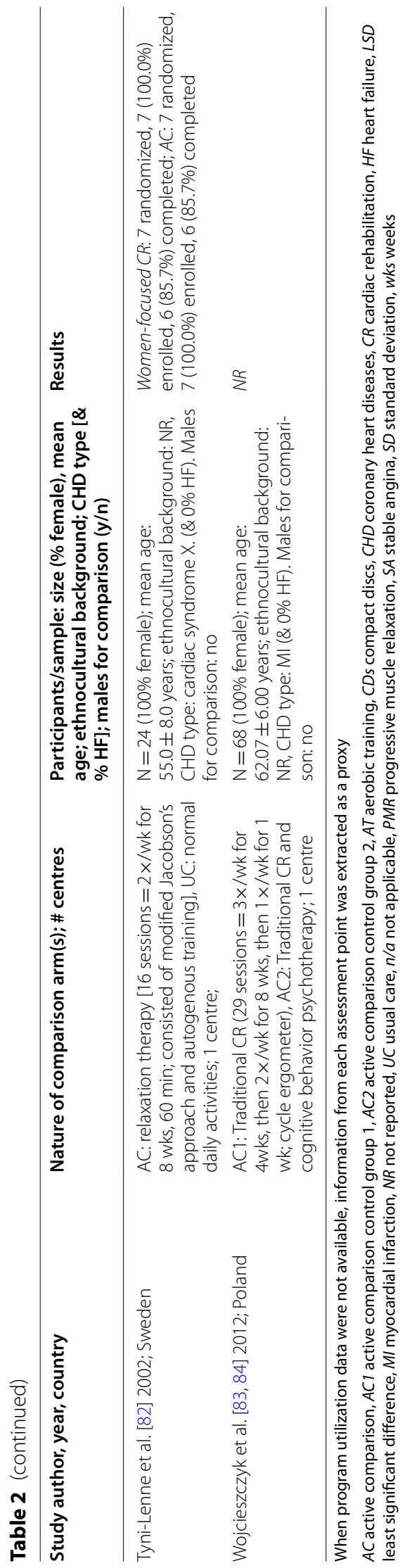


there were fewer calls in the home-based model than site visits in the supervised models [64].

In non-randomized studies, one Canadian study showed women enrolled in mixed-sex CR adhered to a significantly greater proportion $(58.8 \pm 28.9 \%$ of sessions attended/25) of prescribed sessions compared to women-only $(54.3 \pm 26.3 \%$ of sessions attended $/ 25)$ [40]. Azad et al. reported high program adherence in women with heart failure at $87 \%$ of prescribed sessions [45]. In another Canadian study, mean adherence to a women-only model was $75.7 \%$ of sessions, with significantly greater use of CR services (e.g., nutrition, exercise, nursing) among women-only participants compared to matched women in their traditional mixed-sex model [68].

In trials where it was reported, CR completion in women-focused and $\mathrm{AC}$ arms were on average $83.9 \%$ and $76.9 \%$, respectively (Table 2 ). Two non-randomized studies reported on CR completion (i.e., attendance at postprogram assessment). Again in the Canadian, program completion was significantly greater in both supervised models (i.e., equivalent in women-only and mixed-sex models) when compared to home-based; the authors surmised this was due to the fact that women electing homebased services would not be readily-available to come on site for a post-program assessment [40]. Another study in Saudi Arabia reported a women-only CR completion rate of $54.3 \%$ [60].

With regard to satisfaction, there was 1 study assessing this outcome. In the CR4HER trial, participants were significantly more comfortable in their workout attire and perceived the environment as less competitive in the women-only program compared to traditional CR [21]. Yet, ratings of satisfaction were high across all models. Model preference did not differ between mixed-sex and women-only (41.9\%, although this was much higher than for home-based at 16.2\%); Ultimately, women preferred the model they attended however.

\section{Discussion}

To our knowledge, this is the first full review investigating the nature of women-focused CR, seeking to establish global availability, common features, access/utilization by women, and satisfaction. Women-focused CR is not widely available; as established, any $C R$ is insufficiently available [85], and in the countries where CR is available, only about $40 \%$ have any women-focused CR, with most programs in the countries not offering it. This renders women's-focused CR highly inaccessible, particularly given less than $1 / 3$ of the programs used any form of technology so could not reach women beyond their locality (if women had the hardware and proclivity to do so, which requires further study).
It could be this limited availability that explains why so few women are aware of women-focused CR (they are hardly aware any CR exists) $[19,87]$, and hence be aware they can access it [70]. Accessibility is also limited in that it is offered less frequently than traditional mixed-sex CR [21]. This can be particulary problematic for women who are working or have caregiving responsibilities [40], hence offering women-focused programming virtually or asynchronously should be explored.

As summarized in Fig. 2, in about half of studies, the women-focused programming was delivered across the full program, and for the remainder it was a part. In $60 \%$ of studies, the CR intervention was for women only, and for the remainder men were involved as well. Only a third had content tailored to women, most commonly education or psychosocial programming. Indeed, about $60 \%$ had any psychosocial component, despite desire for this in women [20]. In less than one-fifth of studies were non-traditional forms of exercise offered, again despite this preference by women [20]. This was surprising, and suggests there may be challenges for programs in safely, affordably and/or equitably offering such programming; future research should investigate program-level barriers to offering modes of exercise preferred by women. Finally, given women often desire social interaction [20], it was appropriate most programming was delivered in a group; it may be desirable to do this virtually more commonly in future to augment accessibility for women [78]. It is hoped with this information the CR community can come to consensus on what is considered women-focused $\mathrm{CR}$, with our suggestion that it refers to programs: (a) with at least some $C R$ components with $\geq 50 \%$ women, and (b) comprising some form(s) of tailoring to meet women's needs or preferences (e.g., fulsome psychosocial screening and programming, education content, and/or forms of exercise). Moreover, (c) setting/mode of delivery (i.e., to address women's common transportation barriers and time constraints related to caregiving responsibilities, respect their preference for more privacy) as well as (d) clinician sex, disciplines represented on the team (e.g., staff with specialization in women and CVD, and in mental health), who deliver patient-centered care for women [88-90], should also be considered.

Women-focused CR delivery materials were provided in few studies unfortunately, hampering replication. While practical direction on how to develop womenfocused CR is needed, some preliminary insights can be gleaned in the literature. Notably, Price et al. applied 6 principles for women's health to inform their womenonly and tailored CR program development [23]. The principles included: empowering women (e.g., encouragement to strengthen personal resources, personal goal setting, empathic environment), that health services 


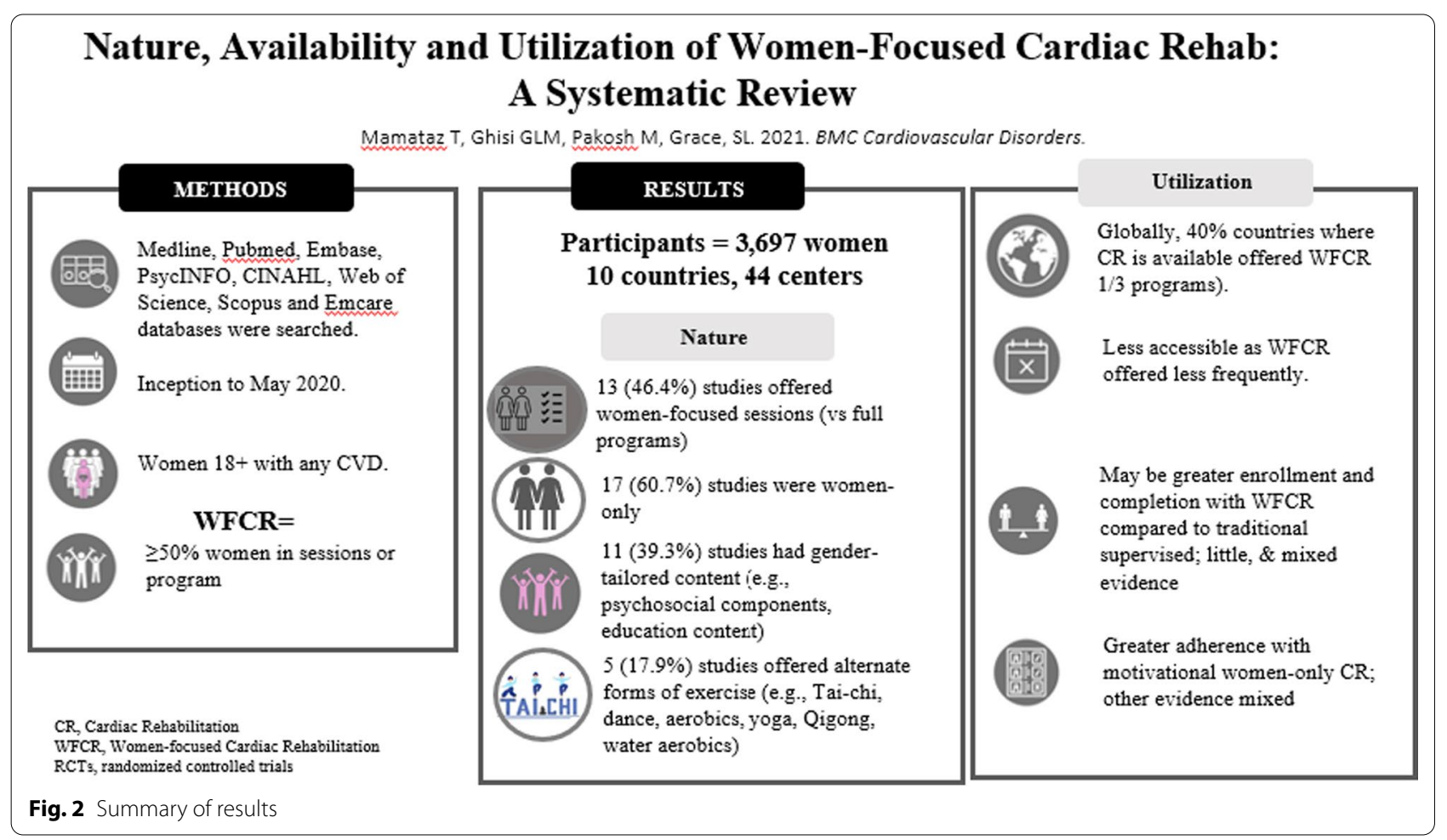

are defined broadly and are accessible (e.g., evening classes, cultural sensitivity), that care is collaborative and patient-centered [88-90], and that innovative and creative approaches are used to meet women's needs. A narrative review is available on ways in which community and home-based programs could better meet women's needs, such as offering appealing forms of exercise [91], offering flexible timing and setting, as well as promoting social interactions [24]. With the COVID-19 pandemic, our program delivers weekly women-focused CR sessions, based on our validated patient education program [92-94], which are freely available online (https://www. healtheuniversity.ca/EN/CardiacCollege/Pages/WomenLearn-Online.aspx). A recently-published paper presents development and evaluation of a theoretically-based mobile phone-based women-focused CR program using machine learning [78]; preliminary engagement and walking results are promising.

With regard to adherence to these programs once women access them, the findings are mixed (Fig. 2). Overall, results seem to suggest that women are more likely to adhere where programs have some form of tailoring [51], and it may not be the "women-only" aspect that makes a difference $[40,64,68]$. Given women do not like to experience pain or fatigue with exercise, important questions regarding adherence to exercise related to intensity of prescription and exercise mode also require study. There is grossly insufficient data on differences in program completion. Clearly, more research in this area is needed. Interestingly however, a recent study in Sweden found higher mixed-sex CR enrolment among women than men, which they attributed to the fact that it is one of the most gender-equal countries in the world [95], and hence "traditional" CR may also by design better meet women's needs and preferences. This supports that perhaps CR need not be women-only, but women-tailored.

Unfortunately, only 1 trial with satisfaction data was identified, which assessed a women-only and not gendertailored program; results were equivocal [21]. Perhaps with this first information regarding what is being offered in women-focused CR, as a CR community we can better standardize women-focused CR feature categorization, and start testing what features are related to greater program satisfaction. Development of a consensus statement on best practices could be useful for the field, until more needed research accrues.

Indeed, this review has raised many questions. Several directions for future research have been identified above. Overall, while it is encouraging that 11 trials have now been done in this area, there is little controlled data on utilization and satisfaction. In addition, while womenfocused CR was most often delivered in a clinical setting (which is likely also a function of our inclusion criteria), given home-based CR is inherently "women-only", more research on ways it can be tailored to better meet 
women's needs is needed. Indeed, home-based CR can mitigate some of women's barriers to utilization, and additionally some women prefer it [22]. Although, homebased CR has been historically less available than traditional CR [96], often likely because it is not as commonly reimbursed [97], with the COVID-19 pandemic there has been a massive shift to online delivery [98], with associated advocacy for coverage, rendering this a more possible avenue in future.

If the evidence does warrant it, what kind of womenfocused CR should be scaled up? Based on current knowledge and practice, offering group women-only sessions (not full programs), virtually, in the evenings, tailored to women's psychosocial and educational needs is likely advisable. Based on the evidence, recommendations regarding dose cannot be made, but leveraging peer support could also meet women's preferences, while reducing workload on $\mathrm{CR}$ staff to deliver such specialized programming. Encouraging women to engage in their preferred exercise modality outside of CR would also be helpful, if programs do not have the capacity to offer it; community resource lists could be developed and shared with women [99]. Exploiting technology could expand reach and contain costs, however patient-centred care is still needed, including close attention to clinical status. Finally, considering context would also be important; culture has an impact on women's health behaviours and healthcare utilization [100].

While quality of included studies was generally acceptable, caution is necessary when interpreting the results of this review. First, data extraction was not done independently by two researchers. Second, there was no grey literature search, nor were any trial registries searched for potential studies to include. Third, generalizability is limited. Studies were of small sample size, but cardiac conditions more common in women were represented. Given the estimated availability of CR globally [85], studies identified herein stem from approximately $25 \%$ of the countries that offer women-focused programming, and $10 \%$ of programs [25]. For example, women-focused CR is known to be available in South Africa, Brazil, Chile, Colombia, Paraguay, Uruguay, Afghanistan, Bahrain, Pakistan, Qatar, Belarus, Bosnia, Czech Republic, Turkey, India, Indonesia, mainland China, Malaysia, as well as several European countries [25], yet we do not know what is offered there. Programs in the Eastern Mediterranean in particular were less well-represented in the sample, given the preponderance of women-only programming is delivered there [101]. As women-only CR is culturallyprescribed in the region commonly, more understanding of what is delivered there is urgently needed [100].

In conclusion, half the time women-focused CR involves full programs, including only women, and offering a psychosocial component; as well, in a third of programs content is gender-tailored, and some offer alternative modes of exercise preferred by women. More research is needed to establish the features of women-focused CR that are associated with greater use, satisfaction and outcomes. Given it is not often available, programs may wish to consider offering women-focused sessions virtually, with peer support, addressing women's unique CVD features and psychosocial needs.

\section{Abbreviations \\ AC: Active comparison; CR: Cardiac rehabilitation; ICCPR: International Council of Cardiovascular Prevention and Rehabilitation; INOCA: Ischemia with non-obstructive coronary arteries; PRISMA: Preferred Reporting Items for Systematic Reviews and Meta-Analyses; SCAD: Spontaneous coronary artery dissection; UC: Usual care.}

\section{Supplementary Information}

The online version contains supplementary material available at https://doi. org/10.1186/s12872-021-02267-0.

Additional file 1. Search Appendix.

\section{Acknowledgements}

SLG is supported in her work by the Toronto General \& Toronto Western Hospital Foundation and the Peter Munk Cardiac Centre, University Health Network, Toronto, Canada.

\section{Authors' contributions}

SLG developed and oversaw this review. MP developed and performed all database searches. Studies were screened independently by TM and GLM, with discrepancies resolved by SLG. TM and SLG undertook hand-searching. TM independently extracted data and appraised the quality of included studies, which were checked independently by GLM. TM and SLG drafted the manuscript, and all other authors revised it critically for important intellectual content and accuracy. SLG and TM are responsible for the overall content as guarantors. The corresponding author attests that all listed authors meet authorship criteria, and that no others meeting the criteria have been omitted. All authors read and approved the final manuscript.

\section{Availability of data and materials}

The data used and analysed in this review are publicly-available and shown in the display items.

\section{Declarations}

Ethics approval and consent to participate Not required.

\section{Consent for publication}

Not applicable.

\section{Competing interests}

The authors declare that they have no competing interest.

\section{Author details}

${ }^{1}$ Faculty of Health, York University, Bethune 368, 4700 Keele Street, Toronto, ON M3J 1P3, Canada. ${ }^{2}$ KITE-Toronto Rehabilitation Institute, University Health Network, University of Toronto, Toronto, ON, Canada. ${ }^{3}$ Library \& Information Services, Toronto Rehabilitation Institute, University Health Network, University of Toronto, Toronto, ON, Canada. ${ }^{4}$ Peter Munk Cardiac Centre, KITE-Toronto 
Rehabilitation Institute, University Health Network, University of Toronto, Toronto, ON, Canada.

Received: 4 May 2021 Accepted: 15 September 2021

Published online: 23 September 2021

\section{References}

1. Global Burden of Disease Results Tool|GHDx. http://ghdx.healthdata. org/gbd-results-tool. Accessed 22 Jan 2021.

2. Norris CM, Yip CYY, Nerenberg KA, et al. State of the science in women's cardiovascular disease: a Canadian perspective on the influence of sex and gender. J Am Heart Assoc. 2020;9:e015634.

3. Sharma S, Wood MJ. The global burden of cardiovascular disease in women. Curr Treat Options Cardiovasc Med. 2018;20:81.

4. Wenger NK. Cardiovascular disease in women: understanding the journey. Clin Chem. 2021;67:24-9.

5. Cho L, Davis M, Elgendy I, et al. Summary of updated recommendations for primary prevention of cardiovascular disease in women: JACC stateof-the-art review. J Am Coll Cardiol. 2020;75:2602-18.

6. Geraghty L, Figtree GA, Schutte AE, Patel S, Woodward M, Arnott C. Cardiovascular disease in women: from pathophysiology to novel and emerging risk factors. Hear Lung Circ. 2021;30:9-17.

7. Grace SL, Turk-Adawi KI, Contractor A, et al. Cardiac rehabilitation delivery model for low-resource settings. Heart. 2016;102:1449-55.

8. Chaves G, Turk-Adawi K, Supervia M, de Araújo Santiago, Pio C, AbuJeish A-H, Mamataz T, Tarima S, Lopez Jimenez F, Grace SL. Cardiac rehabilitation dose around the world: variation and correlates. Circ Cardiovasc Qual Outcomes. 2020;13:e005453.

9. Anderson L, Oldridge N, Thompson DR, Zwisler A-D, Rees K, Martin N, Taylor RS. Exercise-based cardiac rehabilitation for coronary heart disease: cochrane systematic review and meta-analysis. J Am Coll Cardiol. 2016;67:1-12

10. Francis T, Kabboul N, Rac V, Mitsakakis N, Pechlivanoglou P, Bielecki J, Alter D, Krahn M. The effect of cardiac rehabilitation on health-related quality of life in patients with coronary artery disease: a meta-analysis. Can J Cardiol. 2019;35:352-64.

11. Shields GE, Wells A, Doherty P, Heagerty A, Buck D, Davies LM. Costeffectiveness of cardiac rehabilitation: a systematic review. Heart. 2018;104:1403-10.

12. Mosca L, Benjamin EJ, Berra K, et al. Effectiveness-based guidelines for the prevention of cardiovascular disease in women-2011 update: a guideline from the American Heart Association. Circulation. 2011;123:1243-62.

13. de Araújo S, Pio C, Beckie TM, Varnfield M, et al. Promoting patient utilization of outpatient cardiac rehabilitation: a joint International Council and Canadian Association of Cardiovascular Prevention and Rehabilitation position statement. Int J Cardiol. 2020;298:1-7.

14. Colella TJ, Gravely S, Marzolini S, Grace SL, Francis JA, Oh P, Scott LB. Sex bias in referral of women to outpatient cardiac rehabilitation? A metaanalysis. Eur J Prev Cardiol. 2015;22:423-41.

15. Samayoa L, Grace SL, Gravely S, Scott LB, Marzolini S, Colella TJF. Sex differences in cardiac rehabilitation enrollment: a meta-analysis. Can J Cardiol. 2014;30:793-800.

16. Oosenbrug E, Marinho RP, Zhang J, Marzolini S, Colella TJF, Pakosh M, Grace SL. Sex differences in cardiac rehabilitation adherence: a metaanalysis. Can J Cardiol. 2016;32:1316-24.

17. Tsui CK-Y, Shanmugasegaram S, Jamnik V, Wu G, Grace SL. Variation in patient perceptions of healthcare provider endorsement of cardiac rehabilitation. J Cardiopulm Rehabil Prev. 2012;32:192-7.

18. Grace SL, Gravely-Witte S, Kayaniyil S, Brual J, Suskin N, Stewart DE. A multisite examination of sex differences in cardiac rehabilitation barriers by participation status. J Women's Heal. 2009;18:209-16.

19. Resurrección DM, Motrico E, Rigabert A, Rubio-Valera M, Conejo-Cerón S, Pastor L, Moreno-Peral P. Barriers for nonparticipation and dropout of women in cardiac rehabilitation programs: a systematic review. J Women's Heal. 2017;26:849-59.

20. Moore SM, Kramer FM. Women's and men's preferences for cardiac rehabilitation program features. J Cardiopulm Rehabil. 1996;16:163-8.
21. Andraos C, Arthur HM, Oh P, Chessex C, Brister S, Grace SL. Women's preferences for cardiac rehabilitation program model: a randomized controlled trial. Eur J Prev Cardiol. 2015;22:1513-22.

22. Grace SL, Racco C, Chessex C, Rivera T, Oh P. A narrative review on women and cardiac rehabilitation: program adherence and preferences for alternative models of care. Maturitas. 2010;67:203-8.

23. Price J, Landry M, Rolfe D, Delos-Reyes F, Groff L, Sternberg L. Women's cardiac rehabilitation: improving access using principles of women's health. Can J Cardiovasc Nurs. 2005;1 5:32-41.

24. Vidal-Almela S, Czajkowski B, Prince SA, Chirico D, Way KL, Pipe AL, Reed J. Lessons learned from community- and home-based physical activity programs: A narrative review of factors influencing women's participation in cardiac rehabilitation. Eur J Prev Cardiol. 2020;66:1-21.

25. Turk-Adawi K, Supervia M, Lopez-Jimenez F, Adawi A, Sadeghi M, Grace SL. Women-only cardiac rehabilitation delivery around the world. Hear Lung Circ. 2020;30:135-43.

26. Higgins J, Thomas J, Chandler J, Cumpston M, LiT, Page M, Welch V, editors. Cochrane handbook for systematic reviews of interventions version 6.0. Cochrane; 2019.

27. Page MJ, McKenzie JE, Bossuyt PM, et al. The PRISMA 2020 statement: an updated guideline for reporting systematic reviews. BMJ. 2021;372:n71

28. Mamataz T, De Melo Ghisi GL, Pakosh M, Grace SL. Outcomes and cost of women-focused cardiac rehabilitation: a systematic review and meta-analysis. Maturitas Under review; 2021.

29. Hong Q, Pluye P, Fàbregues S, et al. Mixed Methods Appraisal Tool (MMAT), Version; 2018.

30. Campbell M, Mckenzie JE, Sowden A, et al. Synthesis without metaanalysis (SWiM) in systematic reviews: reporting guideline. BMJ. 2020;368:16890.

31. Ghisi GLDM, Chaves GSDS, Bennett A, Lavie CJ, Grace SL. The effects of cardiac rehabilitation on mortality and morbidity in women: a metaanalysis attempt. J Cardiopulm Rehabil Prev. 2019;39:39-42.

32. Supervia M, Medina-Inojosa JR, Yeung C, Lopez-Jimenez F, Squires RW Perez-Terzic CM, Brewer LC, Leth SE, Thomas RJ. Cardiac rehabilitation for women: a systematic review of barriers and solutions. Mayo Clin Proc. 2017:92:565-77.

33. Chowdhury M, Heald FA, Sanchez-Delgado JC, Pakosh M, JacomeHortua AM, Grace SL. The effects of maintenance cardiac rehabilitation: A systematic review and Meta-analysis, with a focus on sex. Hear Lung. 2021;50:504-24.

34. Bittner V. Cardiac rehabilitation for women. In: Adv. Exp. Med. Biol. Springer, New York, pp 565-577; 2018.

35. Feizi A, Ghaderi C, Dehghani MR, Khalkhali HR, Sheikhi S. Effect of phase III cardiac rehabilitation and relaxation on the quality of life in patients with cardiac syndrome X. Iran J Nurs Midwifery Res. 2012;17:547-52.

36. Mahmoodian M, Sheikhvatan M, Sadeghian S, Salarifar M.Lucrative effects of cardiac rehabilitation on exercise capacity and quality of life in anxious depressed women undergoing coronary artery bypass grafting. In: Eur. Heart J. Oxford University Press; 2012. P. 1059.

37. Sadeghi M, Ghashghaei FE, Roohafza H. Comparing the effects of a cardiac rehabilitation program on functional capacity of obese and non-obese women with coronary artery disease. Arya Atheroscler. 2012;8:55-8.

38. Shabani R, Gaeini AA, Nikoo MR, Nikbackt H, Sadegifar M. Effect of cardiac rehabilitation program on exercise capacity in women undergoing coronary artery bypass graft in Hamadan-Iran. Int J Prev Med. 2010;1:247-51.

39. Madison HE. What women want to know: assessing the value, relevance, and efficacy of a self-management intervention for rural women with coronary heart disease. Open Access Dis. 2010;289:66.

40. Heald F, Marzolini S, Colella TJ, Oh P, Nijhawan R, Grace SL.Women choosing mixed-sex women-only, and home-based cardiac rehabilitation models and impact on utilization. Women Health Under review; 2021.

41. Heald F, Marzolini S, Colella TJF, Oh P, Nijhawan R, Grace SL. Women's outcomes following women-only, mixed-sex and home-based cardiac rehabilitation participation and comparison by sex. BMC Womens Health Under review; 2021.

42. Andersson A, Sundel KL, Unden AL, Schenck-Gustafsson K, Eriksson I. A five-year rehabilitation programme for younger women after a 
coronary event reduces the need for hospital care. Scand J Public Health. 2010;38:566-73.

43. Arthur HM, Gunn E, Thorpe KE, Ginis KM, Mataseje L, McCartney N, McKelvie RS. Effect of aerobic vs combined aerobic-strength training on 1 -year, post-cardiac rehabilitation outcomes in women after a cardiac event. J Rehabil Med. 2007;39:730-5.

44. Asbury EA, Slattery C, Grant A, Evans L, Barbir M, Collins P. Cardiac rehabilitation for the treatment of women with chest pain and normal coronary arteries. Menopause. 2008;15:454-60.

45. Azad NA, Bouchard K, Mayhew A, Carter M, Molnar FJ. Safety and predictors of adherence of a new rehabilitation program for older women with congestive heart failure. J Geriatr Cardiol. 2012;9:243-6.

46. Beckie TM, Fletcher GF, Beckstead JW, Schocken DD, Evans ME. Adverse baseline physiological and psychosocial profiles of women enrolled in a cardiac rehabilitation clinical trial. J Cardiopulm Rehabil Prev. 2008;28:52-60.

47. Beckie TM, Beckstead JW. The effects of a cardiac rehabilitation program tailored for women on global quality of life: a randomized clinical trial. J Women's Heal. 2010;19:1977-85.

48. Beckie TM, Beckstead JW, Schocken DD, Evans ME, Fletcher GF. The effects of a tailored cardiac rehabilitation program on depressive symptoms in women: a randomized clinical trial. Int J Nurs Stud. 2011;48:3-12.

49. Beckie TM, Beckstead JW, Schocken DD, Evans ME, Fletcher GF. The effects of a cardiac rehabilitation program tailored for women on their perceptions of health: a randomized clinical trial. J Cardiopulm Rehabil Prev. 2012;31:25-34.

50. Beckie TM, Beckstead JW, Groer MW. The influence of cardiac rehabilitation on inflammation and metabolic syndrome in women with coronary heart disease. J Cardiovasc Nurs. 2010;25:52-60.

51. Beckie TM, Beckstead JW. Predicting cardiac rehabilitation attendance in a gender-tailored randomized clinical trial. J Cardiopulm Rehabil Prev. 2010;30:147-56.

52. Beckie TM, Beckstead JW, Kip KE, Fletcher G. Improvements in heart rate recovery among women after cardiac rehabilitation completion. J Cardiovasc Nurs. 2014;29:38-47.

53. Beckie TM, Beckstead JW, Kip K, Fletcher G. Physiological and exercise capacity improvements in women completing cardiac rehabilitation. J Cardiopulm Rehabil Prev. 2013;33:16-25.

54. Chou AY, Prakash R, Rajala J, Birnie T, Isserow S, Taylor CM, Ignaszewsk A, Chan S, Starovoytov A, Saw J. The first dedicated cardiac rehabilitation program for patients with spontaneous coronary artery dissection: description and initial results. Can J Cardiol. 2016;32:554-60.

55. Clark NM, Janz NK, Dodge JA, Lin X, Trabert BL, Kraciroti N, Mosca L, Wheeler JRC, Keteyian S, Liang J. Heart disease management by patients: Does intervention format matter? Heal Educ Behav. 2009;36:394-409

56. Wheeler JRC. Can a disease self-management program reduce health care costs? The case of older women with heart disease. Med Care. 2003:41:706-15

57. Janz NK, Dodge JA, Janevic MR, Lin X, Donaldson AE, Clark NM. Understanding and reducing stress and psychological distress in older women with heart disease. JWomen Aging. 2004;16:19-38.

58. Gallant MP, Pettinger TM, Coyle CL, Spokane LS. Results of a community translation of the "women Take PRIDE" heart disease self-management program. J Appl Gerontol. 2015;34:244-62.

59. Davidson P, Digiacomo M, Zecchin R, Clarke M, Paul G, Lamb K, Hancock K, Chang E, Daly J. A cardiac rehabilitation program to improve psychosocial outcomes of women with heart disease. J Womens Health. 2008:17:123-34

60. Eyada M, Atwa M. Sexual function in female patients with unstable angina or non-ST-elevation myocardial infarction. J Sex Med. 2007;4:1373-80

61. Gary R. Exercise self-efficacy in older women with diastolic heart failure: results of a walking program and education intervention. J Gerontol Nurs. 2006:32:31.

62. Gary RA, Sueta CA, Dougherty M, Rosenberg B, Cheek D, Preisser J, Neelon V, McMurray R. Home-based exercise improves functional performance and quality of life in women with diastolic heart failure. Hear Lung. 2004;33:210-8.
63. Gary RA. The effectiveness of a home-based exercise program in older women with diastolic heart failure. Chapel Hill: University of North Carolina; 2003.

64. Grace SL, Midence L, Oh P, Brister S, Chessex C, Stewart DE, Arthur HM. Cardiac rehabilitation program adherence and functional capacity among women: a randomized controlled trial. Mayo Clin Proc. 2016;91:140-8.

65. Midence L, Oh P, Grace SL. Women's risk factor control by cardiac rehabilitation program model: a randomized controlled trial. J Cardiopulm Rehabil Prev. 2015;35:374-5.

66. Midence L, Arthur HM, Oh P, Stewart DE, Grace SL. Women's health behaviours and psychosocial well-being by cardiac rehabilitation program model: a randomized controlled trial. Can J Cardiol. 2016;32:956-62.

67. Midence L, Oh P, Grace SL. Women's cardiac rehabilitation barriers by cardiac rehabilitation program model: a randomized controlled trial. J Cardiopulm Rehabiliation Prev. 2015;35:367.

68. Gunn E, Bray S, Mataseje L, Aquila E. Psychosocial outcomes and adherence in a women's only exercise and education cardiac rehabilitation program. In: Can. Assoc. Card. Rehabil. Assoc. Annu. Meet. Sci. Abstr. Journal of Cardiopulmonary Rehabilitation \& Prevention, Quebec City, PQ; 2007. p. 345.

69. Kennedy MD, Haykowsky M, Daub B, Van Lohuizen K, Knapik G, Black B. Effects of a comprehensive cardiac rehabilitation program on quality of life and exercise tolerance in women: a retrospective analysis. Curr Control Trials Cardiovasc Med. 2003:4:1.

70. Rolfe DE, Sutton EJ, Landry M, Sternberg L, Price DJA. Women's experiences accessing a women-centered cardiac rehabilitation program a qualitative study. J Cardiovasc Nurs. 2010;25:332-41.

71. Sutton EJ, Rolfe DE, Landry M, Sternberg L, Price JAD, Phd MA, Msc B, Student P. Cardiac rehabilitation and the therapeutic environment: the importance of physical, social, and symbolic safety for programme participation among women. J Adv Nurs. 2012;68:1834-46.

72. Landry M, Delos-Reyes F, Harvey P, Price J. Long-term clinical effectiveness of a cardiac rehabilitation program designed for women: 6-month and 12-month post intervention follow-up review. Can J Cardiol. 2015;31:S265.

73. Reed JL, Keast ML. Dance-based aerobic interval training for women in cardiovascular rehabilitation. J Cardiopulm Rehabiliation Prev. 2015;35:370.

74. Reed JL, Keast ML, Beanlands RA, Blais AZ, Clarke AE, Pipe AL, Tulloch $H E$. The effects of aerobic interval training and moderate-to-vigorous intensity continuous exercise on mental and physical health in women with heart disease. Eur J Prev Cardiol. 2019:26:211-4.

75. Ghashghaei FE, Sadeghi M, Mostafavi S, Heidari H, Sarrafzadegan N. The effect of the cardiac rehabilitation program on obese and non-obese females with coronary heart disease. Adv Biomed Res. 2012;17:1-10.

76. Ghashghaei FE, Sadeghi M, Rabiei K, Roohafza H, Sarrafzadegan N. Gender differences in risk factors of obese patients after cardiac rehabilitation program. Iran J Nurs Midwifery Res. 2012;17:381-5.

77. Golshahi J, Sadeghi M, Ghashghaei F, Roohafza H, Pourmoghaddas A. Is rehabilitation program more effective in obese women with coronary artery disease? J Isfahan Med Sch. 2014;294:1142-8.

78. Sengupta A, Beckie T, Dutta K, Dey A, Chellappan S. A mobile health intervention system for women with coronary heart disease: usability study. JMIR Form Res. 2020;4:e16420.

79. Silber TC, Tweet MS, Bowman MJ, Hayes SN, Squires RW. Cardiac rehabilitation after spontaneous coronary artery dissection. J Cardiopulm Rehabil Prev. 2015;35:328-33.

80. Szot W, Zajac J, Kubinyi A, Kostkiewicz M. The effects of cardiac rehabilitation on overall physical capacity and myocardial perfusion in women with microvascular angina. Kardiol Pol. 2016;74:431-8.

81. Tsai CC, Li AH, Tu CM, Hwang KL, Jeng C. Effectiveness of a tailored lifestyle management program for middle-aged women with coronary artery disease: a preliminary study. J Nurs Res. 2019;27:e5.

82. Tyni-Lenne R, Stryjan S, Eriksson B, Berglund M, Sylven C. Beneficial therapeutic effects of physical training and relaxation therapy in women with coronary syndrome X. Physiother Res Int. 2002;7:35-43.

83. Wojcieszczyk J, Szczepanska-Gieracha J, Wojtynska R, Kalka D, Bugaj R GrzebieniakT, Kucharski W, Wozniewski M. Impact of different cardiac 
rehabilitation (CR) programs on quality of life and depression in women with ischemic heart disease (IHD). Eur Psychiatry. 2012;27:1.

84. Wojcieszczyk J, Kalka D, Bugaj R, Szczepanska-Gieracha J, Grzebieniak T, Kucharski W, Kropielnicka K, Wozniewski M. Impact of different cardiac rehabilitation programs on exertion tolerance, quality of life and depression in women with ischemic heart disease. Eur J Prev Cardiol. 2012;19:s28.

85. Turk-Adawi K, Supervia M, Lopez-Jimenez F, et al. Cardiac rehabilitation availability and density around the globe. EClinicalMedicine. 2019;13:31-45.

86. World Bank Country and Lending Groups—World Bank Data Help Desk. https://datahelpdesk.worldbank.org/knowledgebase/articles/906519world-bank-country-and-lending-groups. Accessed 22 Jan 2021.

87. Grace SL, Evindar A, Brooks D, Jaglal S, Abramson BL, Nolan R. Increasing patient-initiation of cardiac rehabilitation referral in female percutaneous coronary intervention patients. Can J Cardiovasc Nurs. 2005;15:23-7.

88. Ramlakhan JU, Foster AM, Grace SL, Green CR, Stewart DE, Gagliardi AR. What constitutes patient-centred care for women: a theoretical rapid review. Int J Equity Health. 2019;18:182.

89. Gagliardi AR, Nyhof BB, Dunn S, Grace SL, Green C, Stewart DE, Wright FC. How is patient-centred care conceptualized in women's health: a scoping review. BMC Womens Health. 2019;19:156.

90. Filler T, Dunn S, Grace SL, Straus SE, Stewart DE, Gagliardi AR. Multi-level strategies to tailor patient-centred care for women: qualitative interviews with clinicians. BMC Health Serv Res. 2020;20:212.

91. Murphy BM, Zaman S, Tucker K, Alvarenga M, Morrison-Jack J, Higgins R, Le Grande M, Nasis A, Jackson AC. Enhancing the appeal of cardiac rehabilitation for women: development and pilot testing of a womenonly yoga cardiac rehabilitation programme. Eur J Cardiovasc Nurs. zvab008; 2021.

92. de Ghisi GL, Rouleau F, Ross MK, Dufour-Doiron M, Belliveau SL, Brideau JR, Aultman C, Thomas S, Colella T, Oh P. Effectiveness of an education intervention among cardiac rehabilitation patients in Canada: a multisite study. CJC Open. 2020;2:214-21.
93. Chaves GSS, Ghisi GLM, Grace SL, Oh P, Ribeiro AL, Britto RR. Effects of comprehensive cardiac rehabilitation on functional capacity and cardiovascular risk factors in Brazilians assisted by public health care: Protocol for a randomized controlled trial. Braz J Phys Ther. 2016;20:592-600.

94. de Ghisi GL, M, Britto R, Servio TC, et al. Perceptions of cardiology administrators about cardiac rehabilitation in South America and the Caribbean. J Cardiopulm Rehabil Prev. 2017;37:268-73.

95. Borg S, Öberg B, Leosdottir M, Lindolm D, Nilsson L, Bäck M. Factors associated with non-attendance at exercise-based cardiac rehabilitation. BMC Sports Sci Med Rehabil. 2019;11:1-10.

96. de Melo L, Ghisi G, Pesah E, Turk-Adawi K, et al. Cardiac rehabilitation models around the globe. J Clin Med. 2018;7:260.

97. Moghei M, Pesah E, Turk-Adawi K, Supervia M, Jimenez FL, Schraa E, Grace SL. Funding sources and costs to deliver cardiac rehabilitation around the globe: drivers and barriers. Int J Cardiol. 2019;276:278-86.

98. Ghisi GLM, Xu Z, Liu X, et al.Impacts of the COVID-19 pandemic on cardiac rehabilitation delivery around the world. Glob Heart Under review; 2021.

99. Reed JL, Harris JM, Midence L, Yee EB, Grace SL. Evaluating the heart wise exercise ${ }^{\mathrm{TM}}$ program: a model for safe community exercise programming. BMC Public Health. 2016;16:190.

100. Donnelly TT, Al Suwaidi J, Al Bulushi A, Al Enazi N, Yassin K, Rehman AM, Abu Hassan A, Idris Z. The influence of cultural and social factors on healthy lifestyle of Arabic women. Avicenna. 2011;3:1-13.

101. Turk-Adawi K, Supervia M, Pesah E, et al. Availability and delivery of cardiac rehabilitation in the Eastern Mediterranean Region: How does it compare globally? Int J Cardiol. 2019;285:147-53.

\section{Publisher's Note}

Springer Nature remains neutral with regard to jurisdictional claims in published maps and institutional affiliations.
Ready to submit your research? Choose BMC and benefit from:

- fast, convenient online submission

- thorough peer review by experienced researchers in your field

- rapid publication on acceptance

- support for research data, including large and complex data types

- gold Open Access which fosters wider collaboration and increased citations

- maximum visibility for your research: over 100M website views per year

At BMC, research is always in progress.

Learn more biomedcentral.com/submissions 